\title{
HPV genotyping in patients undergoing colposcopy- guided cervical biopsy and ECC using reference smear and pathology results
}

\section{Ahmet Cetin}

Health Science Univercity, Haseki Teaching and Research Hospital, Department of Gynecologic Oncology.

Derya Sivri Aydin ( $\square$ deryasivri@hotmail.com )

Haseki Eğitim ve Araştırma Hastanesi https://orcid.org/0000-0002-7283-0930

\section{Research article}

Keywords: cervical intraepithelial neoplasia, human papillomavirus, pap smear

Posted Date: June 14th, 2019

DOI: https://doi.org/10.21203/rs.2.10302/v1

License: (c) (i) This work is licensed under a Creative Commons Attribution 4.0 International License.

Read Full License 


\section{Abstract}

Background: The cervical cytology, HPV presence and HPV genotyping used for cervical cancer screening are the guiding lights in predicting the risk of developing the disease now or in the near future and they can be used in deciding how to manage the patient. In our study, we aimed to determine the rate of HPV types in presence of abnormal cervical smear results and preinvasive lesions and to obtain data to help predict the risk of cervical pathology according to HPV genotyping in our population. Materials and methods: In this retrospective case series, 520 consecutive patients were included in the study who underwent colposcopy in the gynecologic oncology clinic. The most common HPV types were determined in patients with abnormal cytology results in cervical smear and with CIN2 or higher in cervical biopsy results. Results: A total of 279 patients were tested positive for HPV. 70 (25.1\%) of the patients were HPV type 16, $34(12.2 \%)$ were type 18 and $134(47.0 \%)$ of the patients were tested positive for other high-risk HPV types. The most frequent other high-risk HPV type was type 39 (7.9\%). Reference smear results identified 239 patients (48.8\%) as ASCUS, 117 patients (23.9\%) as LSIL, 19 patients (3.9\%) as HSIL and 115 patients $(23.5 \%)$ as normal. The incidence of HPV 16 and 18 infection in patients with abnormal smear results was $26.8 \%$. Punch biopsy pathology results that revealed CIN1 was present in $48.4 \%$, CIN2 or CIN3 in $8.1 \%$, squamous cell carcinoma in $1.1 \%$ and cervicitis in $30.4 \%$ of the patients. In $89.2 \%$ of the patients whose biopsy results were CIN2-3 or squamous cell cancer, HPV types were 16 and 18. Conclusion: As types 16 and 18 positivity in patients with ASCUS was $26.8 \%$, we suggest that performing colposcopy directly in all HPV positive cases as recommended in ASCCP guidelines must be questioned and HPV genotyping must be performed before colposcopy in patients with ASCUS.

\section{Background}

High-risk (HR) human papillomavirus (HPV) plays a major role in development of cervical neoplasia and can be detected in $99.7 \%$ of these cancers. HR HPV types are $16,18,31,33,35,39,45,51,52,56,58$, 59,66, 68, 69, 82 and low-risk (LR) HPV types are 6, 11, 40, 42, 43, 44, 53, 54, 61, 72, 73, 81 (3, 4). Persistence of HR strains of HPV infection is the most important determinant factor in cancer development (2). Of these, types 16 and 18 are responsible for the majority of cervical cancer cases (5). The cervical cytology, HPV presence and HPV genotyping used for cervical cancer screening are the guiding lights in predicting the risk of developing the disease now or in the near future and they can be used in deciding how to manage the patient (1). HPV testing is more sensitive than Pap smear in screening and determining the risk of cervical cancer $(6,7)$. Cervical screening tests and colposcopyguided cervical biopsy can effectively help to diagnose cervical intraepithelial neoplasia (CIN), glandular neoplasia or cervical cancer. CIN may be low grade (CIN1) or high grade (CIN2-3) in terms of progression of cervical cancer. Although smear results can be used to identify the CIN status, there is urgent need for studies reporting the outcomes obtained from biopsy results accompanying HPV genotyping.

In our study, we aimed to determine the rate of HPV types in presence of abnormal cervical smear results and preinvasive lesions and to obtain data to help predict the risk of cervical pathology according to HPV genotyping in our population. 


\section{Methods}

In this retrospective case series, a total of 520 consecutive patients who were treated in Haseki Education and Research Hospital's gynecologic oncology department, a tertiary referral hospital, were included in the study between March 2017 and March 2018. The patients were selected according to the criteria of the guideline "The Prevention and Early Detection of Cervical Cancer" (8). The inclusion criteria were as follows: evidence of cytologically normal-HPV type 16 or 18, cytologically atypical squamous cells of undetermined significance (ASCUS)- HR HPV type positive, any HPV type but smear results with lowgrade squamous intraepithelial lesion (LSIL), high-grade squamous intraepithelial lesion (HSIL), atypical squamous cells-cannot exclude HSIL (ASCH), between 21-24 years of age with positive reflex test and colposcopy with a smear ASCUS or LSIL. Patients' age, HPV results, HPV types, reference smear results, colposcopy-guided biopsy and ECC results, type of excision procedure and pathological results were obtained from the hospitals' registry system. HPV genotyping results were available for 279 patients. Colposcopy-guided cervical biopsy was performed in 471 patients with evidence of pathologic finding. In addition, ECC was performed in 447 patients. HPV genotypes were compared according to reference smear results and colposcopy-guided cervical biopsy and ECC.

Ethical approval was obtained from the Haseki Education and Research Hospital Ethics Committee (Number: 274/2018). The mean, standard deviation and percentages were calculated using SPSS version 16 (SPSS Inc. Released 2007. SPSS for Windows, Version 16.0. Chicago, SPSS Inc).

Sample collection:

Cervical cytobrush samples were collected with cervical brushes (Cervix-Brush, Medbar, Izmır, Turkey) and stored in ThinPrep PreservCyt transport medium (Hologic, Inc., Marlborough, MA, USA).

HPV DNA was extracted from a $250 \mu$ sample using QIAvac 24 plus vacuum system (Qiagen, Hilden, Germany) and AmpliLute Liquid Media Extraction Kit (Roche Diagnostics, Mannheim, Germany) following the manufacturer's protocols. The extracted DNA was kept at $-20^{\circ} \mathrm{C}$ until amplification reactions. All samples were tested for HPV DNA presence by biotinylated PGMY09/11L1 consensus primers, the 450bp region of L1 gene was amplified and all samples were genotyped using reverse line blot assay with linear array HPV Genotyping Test (Roche Diagnostics, Mannheim, Germany). Polymerase Chain Reaction (PCR) was performed in GeneAmp ${ }^{\circledR}$ PCR System 9700 Thermal Cycler (Applied Biosystems, Foster City, CA, USA). PCR conditions were: An initial denaturation step of $95^{\circ} \mathrm{C}$ for $9 \mathrm{~min}, 40$ cycles of $95^{\circ} \mathrm{C}$ for $1 \mathrm{~min}$, $55^{\circ} \mathrm{C}$ for $1 \mathrm{~min}$ and $72^{\circ} \mathrm{C}$ for $1 \mathrm{~min}$, followed by a final extension step of $72^{\circ} \mathrm{C}$ for $5 \mathrm{~min}(9)$. The samples were kept at $4^{0} \mathrm{C}$ until further use.

\section{Results}

The mean age of the patients was $40.4( \pm 9.9)$. The demographic data of the patients are given in Table 1. A total of 279 patients were tested positive for HPV. 70 (25.1\%) of the patients were HPV type 16,34 
(12.2\%) were type 18 and 134 (47.0\%) of the patients were tested positive for other HR HPV types (HR HPV types except for type 16 and 18). The most frequent other HR HPV type was type 39 (7.9\%). 44 (15.8\%) patients were either HPV negative or LR HPV positive.

Colposcopic examination was satisfactory in 463 (89.1\%) patients. ECC was performed in 447 (85.9\%) of the patients. Colposcopy guided biopsy was performed in 471 (90.6\%) patients and $279(60.3 \%)$ patients were genotyped for HPV. In 38 (7.3\%) of the patients, Loop Electrosurgical Excision Procedure (LEEP) or Cold Knife Conization (CKC) was performed according to the biopsy results.

Cervical smear results were available for 490 patients and of these the results of 375 (76.5\%) patients were abnormal. The cytology results revealed that 239 (48.8\%) patients had ASCUS, $117(23.9 \%)$ had LSIL, 19 (3.9\%) patients had HSIL and 115 (23.5\%) patients had normal cytology.

HPV genotyping was performed in 139 patients with abnormal smear results and we found that 35 (25.1\%) patients had HPV type 16 which was the most frequent type. 10 (7.2\%) patients had type 18 and other HR HPV types. In 44 (31.7\%) patients, HPV types were either LR positive or negative. In women with abnormal cytological results, HPV tip 16 and 18 infection frequency was $32.4 \%$. In patients with ASCUS smear results, type 16 or 18 positivity was $26.8 \%$. Distribution of the HPV types according to cervical cytological results are shown in Table 2.

Punch biopsy results revealed that 228 (48.4\%) patients had CIN1, 38 (8.1\%) patients had CIN2 or CIN3, $143(30.4 \%)$ patients had cervicitis and $5(1.1 \%)$ patients had squamous cell carcinoma. $57(12.1 \%)$ patients had normal pathological results. In patients who underwent ECC, $27(6.9 \%)$ were diagnosed with CIN1 and 4 (1.0\%) were diagnosed with CIN2 or CIN3. None of the patients were diagnosed with cancer after ECC. CIN1 was detected in 1 of 5 patients who were HPV LR positive or HPV negative. In addition, there were no $\mathrm{CIN} 2 / 3$ or carcinoma cases which were not detected by biopsy but detected by ECC.

Distribution of the HPV types according to colposcopy-guided cervical biopsy and ECC results are shown in Tables 3 and 4.

In 4 of the 5 squamous cell carcinomas detected with colposcopy-guided cervical biopsy, HPV was type 16 positive. In patients with CIN2/3, 66.7\% of the patients had HPV type 16, type 20.8\% had type 18 and $12.5 \%$ had other HR HPV types. In patients who had CIN2/3 and squamous cell carcinoma, $71.4 \%$ of the patients were type 16 and the remaining part had type 18 and other HR HPV types. None of the patients were LR HPV positive or HPV negative.

A total of 38 patients were treated with LEEP or CKC. Of these, $24(63.1 \%)$ were CIN2 and $14(36.9 \%)$ were CIN3. One case was diagnosed with squamous cell carcinoma using LEEP. The smear result of this patient was HSIL and colposcopy-guided biopsy result was CIN2 and colposcopy performed in this patient was reported to be unsatisfactory. CIN2/3 was detected in 29 and CIN1 was detected in 2 patients after LEEP treatment. The remaining 5 patients had cervicitis.

\section{Discussion}


The incidence of HPV infection in patients with abnormal cervical cytology results, which is the most common cause of cervical cancer, has been reported between 28.8-61.3\% (10-12). In our study, the incidence of HR HPV infection was $68.3 \%$ in women with abnormal cervical cytology results and HPV type 16 or 18 positivity was $26.8 \%$. In addition, $71.4 \%$ of the patients who had CIN2/3 and squamous cell carcinoma were HPV type 16 positive while type 18 and other HR types were responsible for the remaining part. Cervical cancer screening guidelines recommend HPV testing as a co-test with cervical cytology or as a reflex test when the Pap test result is ASC-US in women aged between 30 to 64 years. (13). The ASCCP's guidelines recommend colposcopy for all HPV-positive women regardless of the genotyping when ASCUS is present (1). HPV genotyping positive for strains 16 and/or 18 signals a high risk of current or future high-grade cervical neoplasia (14-16). HPV type 16 is responsible for $55-60 \%$ of all cervical cancers. Type 18 and other HR HPV types are responsible for $10-15 \%$ and $25-35 \%$ of all cervical cancers, respectively (17-19). Considering the fact that the HPV types 16 and 18 positivity in patients with ASCUS was $26.8 \%$ and a vast majority (89.2\%) of the patients had types 16 and 18 in lesions with CIN2 or higher in our patient group and also the low incidence of cancer progression caused by other HR HPV types reported in the literature, we believe that HPV genotyping must be performed before colposcopy in patients with ASCUS. In literature, presence of HPV types 16 and 18 in patients with ASCUS has been reported as $22.5 \%$, similar to our study $(12,17,18)$. Even though the prevalence of types 16 and 18 is not provided in these studies, the prevalence of HR-HPV in ASCUS has been reported as $18-49 \%$ in different studies (19-22).

In the literature, the most frequent type of HPV abnormal cytological reports has been reported as type 16 in women with abnormal cytological results $(12,17,18)$. In a study from Turkey, HPV types 16 and 18 (35\% and $8.8 \%$, respectively) have been reported as the most frequent types in women with abnormal cytology (12). Another study has reported that HPV type 16 was the most frequent genotype, followed by types 51, 31,52 and 18 (23). In our study, the most frequent HPV type was $16(25.1 \%)$ and types 18 and 39 were present in $12.2 \%$ and $7.9 \%$ of the patients, respectively. Other HR HPV types were positive in $47 \%$ of the patients.

Although HR HPV positivity accompanying abnormal smear results was $31.8 \%$, presence of HR HPV types only in $12.5 \%$ of CIN2/3 cases and absence of other HR HPV types in any of the cancer cases may be due to the lesser contribution of these types to cancer progression when compared with type 16. In a randomized study including 14 countries, HPV types 16 and 33 have been shown to be the most prevalent genotypes contributing to the progression of CIN3+ cervical lesions (24). No HPV type 33 was detected in our patients in spite of the high HPV type 16 frequency.

ECC lets sampling of the endocervical canal. It has been reported that $5-15 \%$ of high-grade CIN patients are diagnosed with ECC sampling (25-27). In our study, we performed ECC in $86 \%$ of our patients and detected CIN2 and CIN3 in 2\% of the patients. There were no CIN2/3 and carcinoma cases that were detected by ECC but not by biopsy. 
To conclude, we suggest that performing colposcopy directly in all HPV positive cases as recommended in ASCCP guidelines must be questioned and HPV genotyping must be performed.

\section{Conclusions}

As types 16 and 18 positivity in patients with ASCUS was $26.8 \%$, we suggest that performing colposcopy directly in all HPV positive cases as recommended in ASCCP guidelines must be questioned and HPV genotyping must be performed before colposcopy in patients with ASCUS.

\section{Abbreviations}

ASCUS atypical squamous cells of undetermined significance

CIN Cervical intraepithelial neoplasia

CKC Cold knife conization

ECC Endocervical currettage

HPV Human papilloma virüs

HSIL High-grade squamous intraepithelial lesion

LEEP Loop electrosurgical excision procedure

LSIL Low-grade squamous intraepithelial lesion

SCC Squamous cell carcinoma

\section{Declarations}

Ethics approval and consent to participate: Ethical approval was obtained from the Haseki Education and Research Hospital Ethics Committee (Number: 274/2018).

Consent to publish: Not applicable.

Availability of data and material: The datasets used and/or analyzed in the current study are available from the corresponding author upon reasonable request.

Competing interests: The authors declare that they have no competing interests.

Funding: The authors declared that this study has received no financial support.

Authors' contributions: All authors contributed to the conception, review of studies, and analysis of data. All authors were involved in drafting and revising the manuscript. All authors approved the final version of 
the manuscript.

Acknowledgements: Not applicable

\section{References}

1. IARC Working Group on the Evaluation of Carcinogenic Risks to Humans. Biological agents. Volume 100 B. A review of human carcinogens. IARC Monogr Eval Carcinog Risks Hum 2012; 100:1-441.

2. Kjaer SK, van den Brule AJ, Paull G, Svare El, Sherman ME, Thomsen BL, et al. Type specific persistence of high risk human papillomavirus (HPV) as indicator of high grade cervical squamous intraepithelial lesions in young women: population based prospective follow up study. CJ BMJ. 2002; 325(7364): 572.

3. Bouvard V, Baan R, Straif K, Grosse Y, Secretan B, Ghissassi FE, et al. A review of human carcinogens part B: biological agents. Lancet Oncol 2009; 10:321-2.

4. Practice Bulletin No. 168: Cervical Cancer Screening and Prevention. Committee on Practice BulletinsGynecology. Obstet Gynecol. 2016; 128: 111-30.

5. Saslow D, Solomon D, Lawson HW, Killackey M, Kulasingam SL, Cain J, et al. ACS-ASCCPASCP Cervical Cancer Guideline Committee. American Cancer

Society, American Society for Colposcopy and Cervical Pathology, and American Society for Clinical Pathology screening guidelines for the prevention and early detection of cervical cancer. CA Cancer J Clin. 2012;62(3):147-72.

6. Huh WK, Ault KA, Chelmow D, Davey DD, Goulart RA, Garcia FA, et al. Use of primary high-risk human papillomavirus testing for cervical cancer screening: interim clinical guidance. J Low Genit Tract Dis. 2015; 19: 91-6.

7. Gupta S, Palmer C, Bik EM, Cardenas JP, Nuñez H, Kraal L, et al. Self-Sampling for Human Papillomavirus Testing: Increased Cervical Cancer Screening Participation and Incorporation in International Screening Programs. Front Public Health. 2018; 9; 6: 77.

8. Saslow D, Solomon D, Lawson HW, Killackey M, Kulasingam SL, Cain JM, et al. American Cancer Society, American Society for Colposcopy and Cervical Pathology, and American Society for Clinical Pathology Screening Guidelines for the Prevention and Early Detection of Cervical Cancer. J Low Genit Tract Dis. 2012; 16: 175-204. Review.

9. Coutlée F, Rouleau D, Petignat P, Ghattas G, Kornegay JR, Schlag P, et al. Enhanced detection and typing of human papillomavirus (HPV) DNA in anogenital samples with PGMY primers and the linear array HPV genotyping test. J Clin Microbiol 2006; 44: 1998-2006.

10. González-Bosquet E, Esteva C, Muñoz-Almagro C, Ferrer P, Pérez M, Lailla JM. Identification of vaccine human papillomavirus geno-types in squamous intraepithelial lesions (CIN2-3) Gynecol Oncol. 2008; 111: 
9-12.

11. Levert M, Clavel C, Graesslin O, Masure M, Birembaut P, Quereux C, et al. Human papillomavirus typing in routine cervical smears. Result from a series of 3778 patients. Gynecol Obstet Fertil. 2000; 28: 722-8.

12. Cilingir IU, Bengisu E, Ağaçfidan A, Koksal MO, Topuz S, Berkman S, et al. Microarray detection of human papilloma virus genotypes among Turkish women with abnormal cytology at a colposcopy unit. $J$ Turk Ger Gynecol Assoc. 2013; 14: 23-7.

13. Massad LS, Einstein MH, Huh WK, Katki HA, Kinney WK, Schiffman M et al. 2012 updated consensus guidelines for the management of abnormal cervical cancer screening tests and cancer precursors Low Genit Tract Dis. 2013;17(5):1-27.

14. Wright TC, Stoler MH, Behrens CM, Sharma A, Zhang G, Wright TL. Primary cervical cancer screening with human papillomavirus: end of study results from the ATHENA study using HPV as the first-line screening test. Gynecol Oncol. 2015;136(2):189,

15. Huh WK, Ault KA, Chelmow D, Davey DD, Goulart RA, Garcia FA, et al. Use of primary high-risk human papillomavirus testing for cervical cancer screening: interim clinical guidance. Gynecol Oncol. 2015;136(2):178.

16. Einstein MH, Garcia FA, Mitchell AL, Day SP, Age-stratified performance of the Cervista HPV 16/18 genotyping test in women with ASC-US cytology. Cancer Epidemiol Biomarkers Prev. 2011;20(6):1185

17. Dursun P, Senger S, Arslan H, Kuşcu E, Ayhan A. Human papillomavirus (HPV) prevalence and types among Turkish women at a gynecology outpatient unit. BMC Infect Dis. 2009; 9: 191.

18. Gultekin M, Zayifoglu KM, Kucukyildiz I, Dundar S, Boztas G, Semra TH, et al. Initial results of population based cervical cancer screening program using HPV testing in one million Turkish women. Int J Cancer 2018; 142: 1952-8.

19. Guo Z, Jia MM, Chen Q, Chen HM, Chen PP, Zhao DM, Ren LY, Sun XB, Zhang SK.Stany MP, Bidus MA, Reed EJ, Kaplan KJ, McHale MT, Rose GS, et al. . The prevalence of HR-HPV DNA in ASC-US Pap smears: a military population study. Gynecol Oncol. 2006; 101:82-5.

20. Fakhreldin M, Elmasry K. Improving the performance of reflex Human Papilloma Virus (HPV) testing in triaging women with atypical squamous cells of undetermined significance (ASCUS): a restrospective study in a tertiary hospital in United Arab Emirates (UAE). Vaccine. 2016;34:823-30.

21. Guo Z, Jia MM, Chen Q, Chen HM, Chen PP, Zhao DM et al. Performance of Different Combination Models of High-Risk HPV Genotyping in Triaging Chinese Women With Atypical Squamous Cells of Undetermined Significance, Front Oncol. 2019; 3;9:202. 
22. Cheng JX, Yao LL, Xiang H, Zhan YJ, Zhou P, Yuan M, et al. Cervical cytology ASCUS patients with HPV detection and clinical value. Clin Exp Obstet Gynecol. 2016;43(4):592-6.

23. Gök M, CoupéVM, Berkhof J, Verheijen RH, Helmerhorst TJ, Hogewoning CJ, et al. HPV16 and increased risk of recurrence after treatment for CIN. Gynecol Oncol. 2007; 104: 273.

24. Unnop J, Xavier C, Suzanne MG, Paulo N, Johanna P, Maria Rowena RR, et al. Natural History of Progression of HPV Infection to Cervical Lesion or Clearance: Analysis of the Control Arm of the Large, Randomised PATRICIA Study HPV PATRICIA Study Group PLoS One. 2013; 8: 79260.

25. Gage JC, Hanson VW, Abbey K, Dippery S, Gardner S, Kubota J, et al. ASCUS LSIL Triage Study (ALTS) Group. Number of cervical biopsies and sensitivity of colposcopy. Obstet Gynecol. 2006; 10: 264.,

26. Pretorius RG, Zhang WH, Belinson JL, Huang MN, Wu LY, Zhang X, et al. Colposcopically directed biopsy, random cervical biopsy, and endocervical curettage in the diagnosis of cervical intraepithelial neoplasia II or worse. Am J Obstet Gynecol. 2004; 191: 430.

27. Solomon D, Stoler M, Jeronimo J, Khan M, Castle P, Schiffman M. Diagnostic utility of endocervical curettage in women undergoing colposcopy for equivocal or low-grade cytologic abnormalities. Obstet Gynecol. 2007; 110: 288.

\section{Tables}

Due to technical limitations, the Tables are only available as a download in the supplemental files section.

\section{Supplementary Files}

This is a list of supplementary files associated with this preprint. Click to download.

- Table4.jpg

- Table2.jpg

- Table1.jpg

- Table3.jpg 